\title{
VISUALIZACIÓN MICROSCÓPICA DE CORDONES DE MICOBACTERIAS EN MEDIO 7H11 Y DIFERENCIACIÓN MEDIANTE TINCIÓN ZIEHL-NEELSEN
}

\author{
MICROSCOPIC VISUALIZATION OF MYCOBACTERIA CORDS IN 7H11 MEDIUM \\ AND DIFFERENTIATION THROUGH ZIEHL-NEELSEN STAIN
}

\author{
Jesús Rojas Jaimes ${ }^{1,2, a}$, Jorge Giraldo-Chavez ${ }^{3, b}$, Yudit Huyhua-Flores ${ }^{3, c}$, Tatiana Caceres-Nakiche ${ }^{3, b}$
}

Se menciona que una persona se contagia por el bacilo de la tuberculosis cada segundo, y que un tercio de la población mundial está actualmente infectada por este bacilo ${ }^{(1)}$. Existen componentes bacterianos como los ácidos grasos ${ }^{(2)}$ y la micosida que estarían vinculados con la forma de la colonia y la fisiología de diversas micobacterias ${ }^{(3)}$.

La identificación de micobacterias consume mucho tiempo en los medios sólidos tradicionales y deberían ser complementadas por técnicas de cultivo rápido como $7 \mathrm{H} 11$ y de tinción como Ziehl-Neelsen, realizadas por un personal altamente entrenado.

La presente galería complementa los hallazgos de artículo publicado por Rojas Jaimes et al. (4), cuyo objetivo fue identificar las diferencias morfológicas en colonias de diferentes especies de micobacterias mediante microscopía de fase invertida en medio sólido $7 \mathrm{H} 11$ y tinción ZiehlNeelsen, con la finalidad de apoyar el diagnóstico en la lucha contra la tuberculosis.

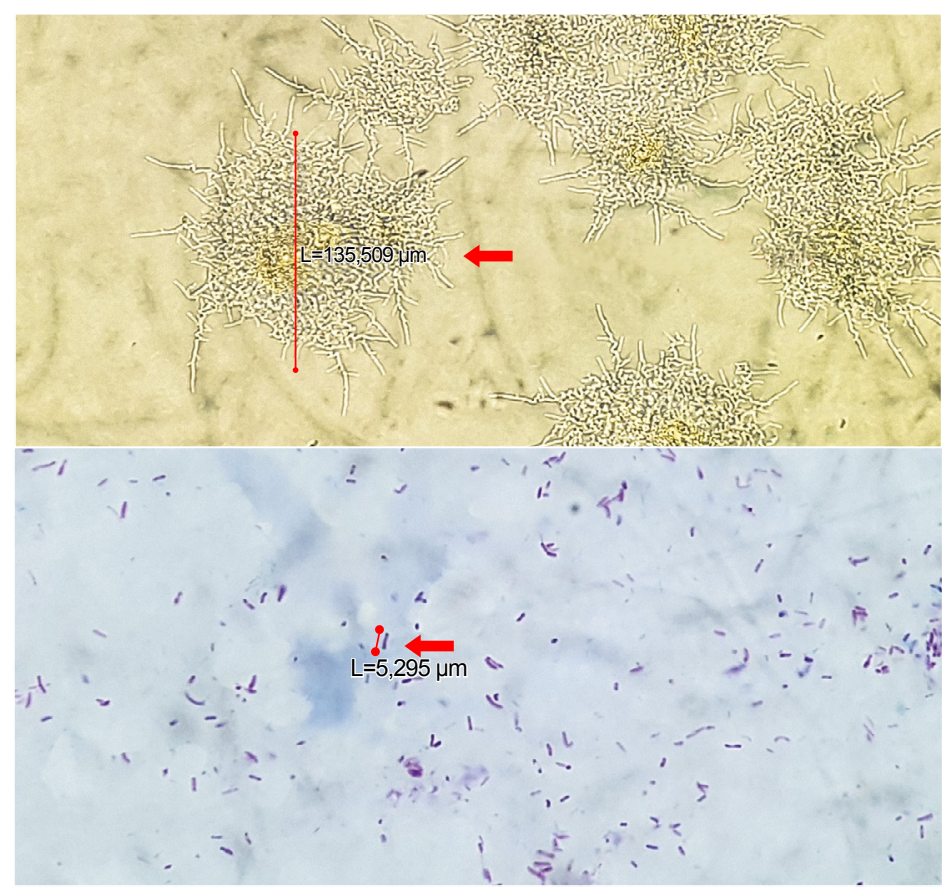

Figura 1. Microfotografía a los 17 días de crecimiento de Mycobacterium fortuitum, se observa la formación de cordones, sin visualización macroscópica a 100X

Escuela de Medicina Humana, Universidad Científica del Sur. Lima, Perú

Facultad de Ciencias Básicas, Universidad Continental. Lima, Perú

Universidad Peruana Cayetano Heredia, Instituto de Enfermedades Tropicales Alexander von Humboldt. Lima, Perú

Magister en Biología Molecular; ${ }^{\mathrm{b}}$ biólogo; ${ }^{\mathrm{c}}$ técnico de laboratorio

Recibido: 15/02/2018 Aprobado: 16/05/2018 En línea: 25/06/2018

Citar como: Rojas Jaimes J, Giraldo-Chavez J, Huyhua-Flores Y, Caceres-Nakiche T. Visualización microscópica de cordones de micobacterias en medio 7H11 y diferenciación mediante tinción Ziehl-Neelsen. Rev Peru Med Exp Salud Publica. 2018;35(2):344-6. doi: 10.17843/rpmesp.2018.352.3475. 


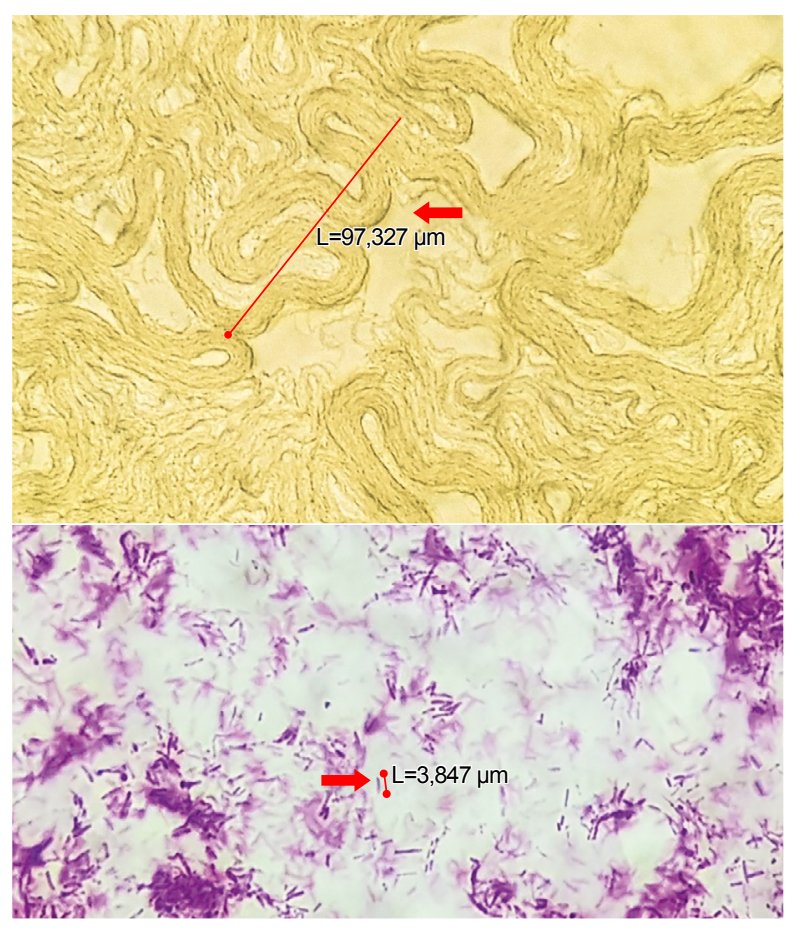

Figura 2. Microfotografía a los tres días de crecimiento, se observan los cordones de una macrocolonia de Mycobacterium chelonae, aumento 100X (foto superior). Lectura Ziehl-Neelsen de Mycobacterium chelonae, aumento 1000X. Bacilos alargados y unicelulares (foto inferior).

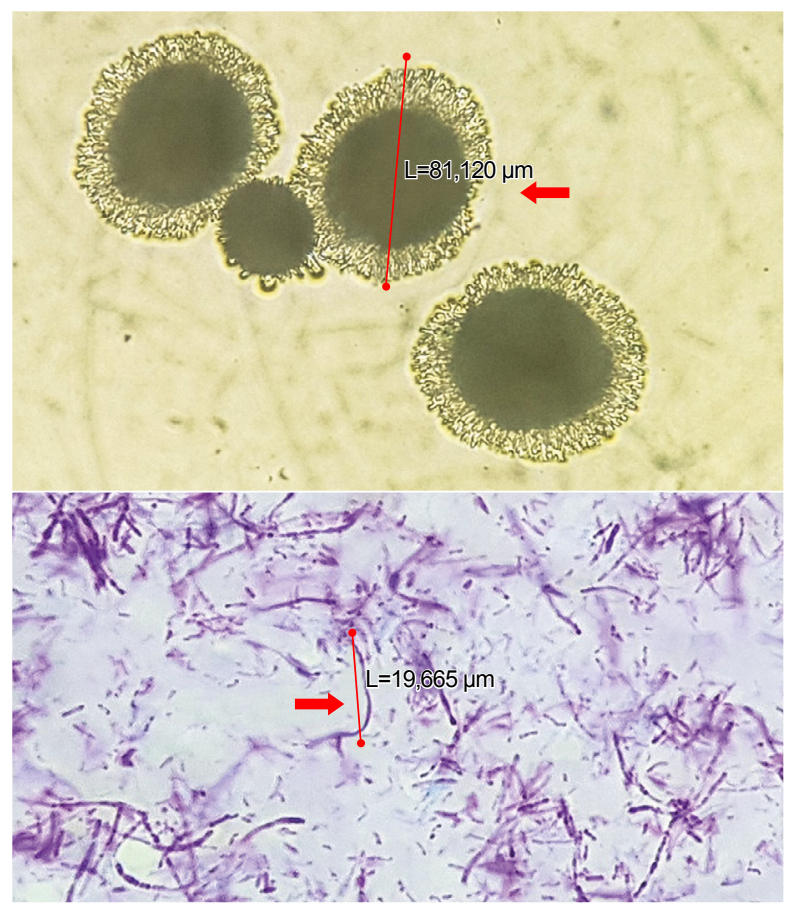

Figura 4. Microfotografía a los 11 días de crecimiento de Mycobacterium gordonae, 100X. Obsérvese los cordones periféricos de las microcolonias (foto superior). Lectura Ziehl-Neelsen de Mycobacterium gordonae, 1000X. Se observan bacilos en cadenas largas (foto inferior).

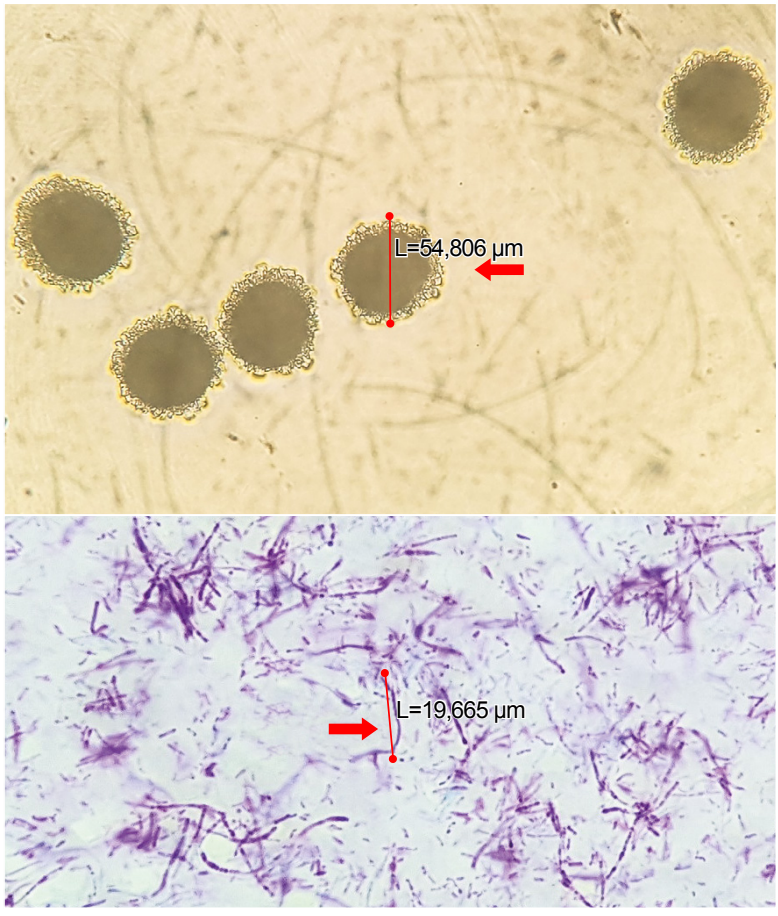

Figura 3. Microfotografía a los 15 días de crecimiento de Mycobacterium marinum, 100X. Obsérvese los cordones periféricos salientes de las microcolonias (foto superior). Lectura Ziehl-Neelsen de Mycobacterium marinum, 1000X. Bacilos unicelulares cortos (foto inferior)

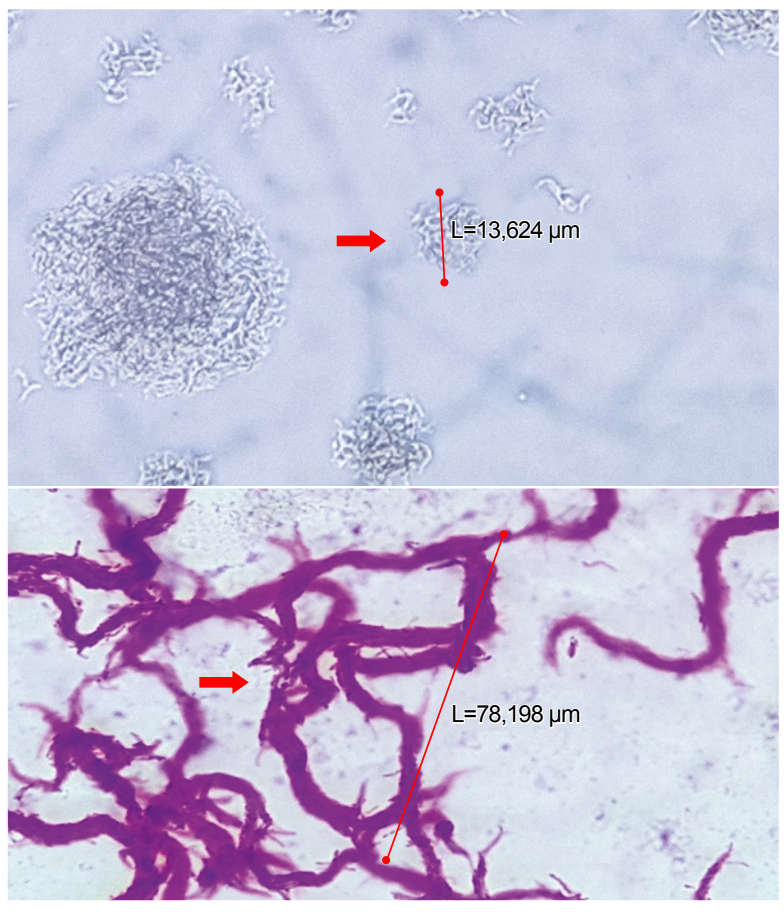

Figura 5. Microfotografía a los 14 días de crecimiento de Mycobacterium tuberculosis, 100X (foto superior). Lectura ZiehlNeelsen de Mycobacterium tuberculosis, 1000X. Se observan cordones clásicos (foto inferior). 


\section{REFERENCIAS BIBLIOGRÁFICAS}

1. Palomino JC, Leao SC, Ritacco V. Tuberculosis 2007 From basic science to patient care. lera edición [Internet], São Paulo: TuberculosisTextbook.com; 2007. Disponible en: http://pdf. flyingpublisher.com/tuberculosis2007.pdf

2. Selvarangan R, Wu WK, Nguyen TT, Carlson LD, Wallis CK, Stiglich SK, et.al. Characterization of a Novel Group of Mycobacteria and Proposal of Mycobacterium sherrisii sp. nov. J Clin Microbiol. 2004; 42(1):52-9.

3. Fregnan GB, Smith DW, Randall HM. Biological and Chemical Studies on mycobacteria relationship of colony morphology to mycoside content for Mycobacterium kansasii and Mycobacterium fortuitum. J Bacteriol. 1961;82:517-27.

4. Rojas Jaimes J, Giraldo-Chavez J, Huyhua-Flores Y, CaceresNakiche T. Identificación de micobacterias en medio sólido mediante microscopía de fase invertida y tinción Ziehl-Neelsen. Rev Peru Med Exp Salud Publica. 2018;35(2)279-84. doi:10.17843/ rpmesp.2018.352.3471.

Correspondencia: Jesús Rojas Jaimes

Dirección: Panamericana Sur 19, Villa EL Salvador 15067. Lima, Perú Teléfono: (511) 993638840

Correo electrónico:jesus.rojas.jaimes@gmail.com 